\title{
Multiple Nerve Damages Because of Occupational Risk Factors
}

\author{
Ismail Boyraz ${ }^{\mathrm{a}, \mathrm{c}}$, Bunyamin Koc ${ }^{\mathrm{a}}$, Hakan Sarman ${ }^{\mathrm{b}}$, Hilal Caglar ${ }^{\mathrm{a}}$
}

\begin{abstract}
Upper extremity problems due to working are frequently encountered. We presented a case of bilateral multiple nerve damages that were thought to be secondary to working and were evaluated to eliminate the probability of presence of other etiological factors. The patient was a press operator and he was performing elbow flexion and wrist extension against resistance at work. He had numbness in the first and second fingers of his right hand and pain in the forearm. His last EMG revealed right median nerve, left median and ulnar palsy, total denervation in the right radial nerve. The patient underwent an operation in the right cubital region. During the operation, compression was found to be due to soft tissue pressure; the radial nerve was released and the neighboring scar tissue was cleaned.
\end{abstract}

Keywords: Multiple nerve damages; Occupational risk factors; Nerve surgery

\section{Introduction}

Upper extremity problems due to working are frequently encountered. Among those are tendinopathies, neuropathies, medial and lateral epicondylitis, and nerve entrapments, which are particularly observed in the elbows and hands. Repetitive movements, working with instruments with vibration effects, compelling types of work with weights of more than $5 \mathrm{~kg}$, and types of work that require a high level of grasping power are among the risk factors [1]. Repetitive movements and chronic obstruction due to local mechanical pressure result in increased

\footnotetext{
Manuscript accepted for publication January 29, 2015

aDepartment of Physical Medicine and Rehabilitation, Bolu Abant Izzet Baysal University Medical School, Bolu, Turkey

bepartment of Orthopedics and Traumatology, Bolu Abant Izzet Baysal University Medical School, Bolu, Turkey

${ }^{\mathrm{c} C o r r e s p o n d i n g ~ A u t h o r: ~ I s m a i l ~ B o y r a z, ~ D e p a r t m e n t ~ o f ~ P h y s i c a l ~ M e d i c i n e ~ a n d ~}$ Rehabilitation, Bolu Abant Izzet Baysal University Medical School, AIBU Physical Therapy and Rehabilitation Training and Research Hospital, Karacasu, Bolu, Turkey. Email: boyraz@yahoo.com
}

doi: http://dx.doi.org/10.14740/jmc2068w pressure in the tunnel and ischemia. An increase by $40 \mathrm{~mm} \mathrm{Hg}$ in the pressure inside the carpal tunnel has been demonstrated in ischemic models with $40^{\circ}$ of wrist extension with compression of $1.2 \mathrm{~kg}$ at $40 \mathrm{mmHg}$. Pressure of $20-30 \mathrm{~mm} \mathrm{Hg}$ results in a decrease in the venous blood flow in acute entrapment models. In addition, pressures of $35-50 \mathrm{~mm} \mathrm{Hg}$ and $70 \mathrm{~mm}$ $\mathrm{Hg}$ result in impairment in the capillary blood flow and total ischemia, respectively, in experimental studies. Furthermore, it is reported that pressure application of $30 \mathrm{~mm} \mathrm{Hg}$ for $4 \mathrm{~h}$ resulted in entrapment neuropathy through an increase in the vascular permeability and thus the development of edema and increased pressure inside the fascicle [2].

Carpal tunnel syndrome is the most frequently seen entrapment neuropathy of the upper extremity; it can be seen simultaneously in both hands and is more common in the $40-60$ years age group. Repetitive movement of the wrist is the most significant risk factor. Cubital tunnel syndrome is the second most common entrapment neuropathy of the upper extremity. Individuals who lean on their elbows at flexion during work and loading on the elbow are at risk and compressive pressure secondary to repetitive movements is among the risk factors. Radial tunnel syndrome is less common among workers. Entrapment is frequently localized at the lateral part of triceps muscle (posterior arm) and at the middle arm. Some of the reasons for entrapment are over use of the triceps muscle, humerus fractures, lesions in the supinator muscle or the presence of a septum between the extensor muscles and external pressures. Frequent compulsive loading, repetitive movements, and heavy working generally result in lateral and medial epicondylitis in patients. Postural loading, low work control, and low socioeconomic support cause lateral epicondylitis, while vibration work more frequently causes medial epicondylitis [3-11].

Herein, we presented a case of bilateral multiple nerve damages that were thought to be secondary to working and were evaluated to eliminate the probability of presence of other etiological factors.

\section{Case Report}

A 34-year-old male patient, who presented to the clinic after a repair of a spontaneous radial nerve injury, was admitted to our clinic for rehabilitation treatment. The patient was a press operator and he was performing elbow flexion and wrist exten- 
sion against resistance at work. He had numbness in the first and second fingers of his right hand on July 1, 2013. A severe right forearm pain that began suddenly at night occurred after 10 days. Cervical, brachial plexus, shoulder and right elbow MRI examinations and an EMG were performed at anotherclinic for diagnosis. His routine blood tests were unremarkable. Narrowing and fused vertebrae of the C3-4 level and central bulging at C5-6 and C6-7 levels were detected in the cervical MRI. Right shoulder MRI and brachial plexus MRI were normal. The radius head was found to be deformed and fused with the ulna. The humeroradial joint space was narrowed and minimal spur formation was seen. Methylprednisolone treatment was started at a dose of $16 \mathrm{mg}$. A repeat EMG was obtained, since his complaints worsened on November 26, 2013. A patchy involvement in the right median nerve and a process resulting in axonal loss and chronic mild radiculopathy at the right $\mathrm{C} 7$ and left $\mathrm{C} 5-6$ roots was detected. Pregabalin was started at a dose of $150 \mathrm{mg}$ twice daily. The EMG obtained on June 31, 2014 revealed a slight improvement in the right lower trunk involvement, while a severe partial lesion at the posterior cord of the middle trunk (distal to the brachioradial muscle) was detected. The EMG performed on February 2, 2014 revealed findings compatible with affected sensory and motor branches of the right median nerve and left median and ulnar sensory filaments, chronic partial axonal damages likely secondary to the wrist deformity, total denervation in the right radial nerve distal to the branch to the brachioradial muscle except to the indicisproprius, and very advanced partial axonal damage to indicisproprius (subacute phase). Since the nerve damage detected by the EMG was severe, the patient underwent an operation in the right cubital region. During the operation, compression was found to be due to soft tissue pressure; the radial nerve was released and the neighboring scar tissue was cleaned.

Upon physical examination, the patient, who was right handed, found that he could not perform total supination in the two forearms; instead, he was capable of only midsupination. No deformities were found in the other joints. His past medical history and family history were unremarkable. Upon neurologic examination, the range of motion at the right elbow and shoulder and muscle strength was complete, while right wrist extension was graded $3 / 5$, flexion was $4 / 5$, second and third finger extension was $2 / 5$ and flexion was $4 / 5$, and thumb flexion and abduction was $2 / 5$. Hypoesthesia was present at the dorsolateral part of the right hand and the dorsal side of the first two fingers. Triceps reflex was normoactive, while brachioradial reflex was absent.

Right forearm strengthening, electrical stimulation, sensory reeducation, and work occupation education treatments were performed. A follow-up EMG obtained at the sixth month while his treatment was ongoing revealed an ongoing process of reinnervation and regeneration in the right radial and median nerves. His muscle strength was increased at the physical examinations performed while the treatment was ongoing.

\section{Discussion}

Local friction, traction, and compression of the nerves during work may cause damage to nerves. Postural loading may cause nerve entrapment of both radial and ulnar nerves; frequent loading mostly causes radial nerve damage; repetitive movements, applying pressure by the palms, and compressions may cause median nerve entrapment. None of the physical factors has a more important role compared to the others. Previous injuries and medical condition of the individual may also change the risk of injury during work. Psychological and social factors and mood disorders also play key roles in the tension injuries due to repetitive movements $[12,13]$.

Intermittent paresthesia and subjective weakness in mild cases, continuous paresthesia and measurable muscle weakness in intermediate cases, and continuous paresthesia, atrophy and marked weakness occur in advanced cases. Spontaneous healing is possible in mild and intermediate cases with preventive measures, while patients with persisting symptoms require treatment. For CTS, surgery is recommended in patients who have intermediate grade symptoms for longer than 12 months with no adequate response to conservative treatment and whose EMG is positive $(+)$ and in EMG positive $(+)$ patients with apparent motor involvement and severe symptoms [14, 15].

Exposed physical factors are quite heterogeneous. Piligian et al reported that risk factors for cubital tunnel were repetitive, sudden elbow flexion, repetitive trauma, and compression on the ulnar sulcus [16]. In another study, occupational risk of ulnar nerve damage is reported to be greater due to holding an instrument at a specific position, obesity, other musculoskeletal system disorders, such as medial epicondylitis, and other nerve compressions [3]. Roquelaure et al stated that physically demanding work, hand-arm vibration, and postural loading were the most important risk factors for radial nerve entrapment [17]. On the other hand, Rogier reported that while stationary working was a risk factor for cubital tunnel, working with the wrist at full extension or static working and work that necessitates loading with more than $1 \mathrm{~kg}$ for more than 10 times in an hour were risk factors for radial nerve entrapment. In a case of a floor parqueting worker who was required to perform repetitive hand movements, bilateral carpal tunnel syndrome at the Guyon's canal was reported, in addition to ulnar nerve entrapment [18].

Neurophysiological evaluations are normal in general in patients in whom weakness is absent. Electromyographic studies may be performed if conservative treatments fail. Ultrasonography can also aid in the diagnosis. An ergonomic setting in work places is required in the treatment of nerve entrapments. Nerve and tendon sliding exercises decrease the risk of a patient undergoing surgery. Healing after surgery can be extended for as long as 2 years [19, 20].

The present case is interesting, as the patient had bilateral multiple nerve damages and occupational circumstances played role as a risk factor in the occurrence of nerve entrapments. Furthermore, the patient had a non-advanced level of elbow contracture. The patient had no prior medical diseases and the tests performed revealed no secondary predisposing conditions. He suffered severe radial nerve damage due to mechanical compression. The patients must be examined carefully in terms of a lot of disorders if the patient has several nerve palsies. 


\section{Disclosure}

There is no source of support or grants for this manuscript, nor potential conflict of interest for any of the authors.

\section{References}

1. van Rijn RM, Huisstede BM, Koes BW, Burdorf A. Associations between work-related factors and specific disorders at the elbow: a systematic literature review. Rheumatology (Oxford). 2009;48(5):528-536.

2. Bozkurt G. Periferik sinir tuzak noropatileri. Turk Norosiruji Dergisi. 2005;15(3):206-219.

3. Descatha A, Leclerc A, Chastang JF, Roquelaure Y. Incidence of ulnar nerve entrapment at the elbow in repetitive work. Scand J Work Environ Health. 2004;30(3):234240.

4. McPherson SA, Meals RA. Cubital tunnel syndrome. Orthop Clin North Am. 1992;23(1):111-123.

5. Mondelli M, Giannini F, Ballerini M, Ginanneschi F, Martorelli E. Incidence of ulnar neuropathy at the elbow in the province of Siena (Italy). J Neurol Sci. 2005;234(12):5-10.

6. Mondelli M, Grippo A, Mariani M, Baldasseroni A, Ansuini R, Ballerini M, Bandinelli C, et al. Carpal tunnel syndrome and ulnar neuropathy at the elbow in floor cleaners. Neurophysiol Clin. 2006;36(4):245-253.

7. Huisstede B, Miedema HS, van Opstal T, de Ronde MT, Verhaar JA, Koes BW. Interventions for treating the radial tunnel syndrome: a systematic review of observational studies. J Hand Surg Am. 2008;33(1):72-78.

8. Huisstede BM, Miedema HS, van Opstal T, de Ronde MT, Kuiper JI, Verhaar JA, Koes BW. Interventions for treating the posterior interosseus nerve syndrome: a systematic review of observational studies. J Peripher Nerv Syst. 2006;11(2):101-110.

9. Konjengbam M, Elangbam J. Radial nerve in the radial tunnel: anatomic sites of entrapment neuropathy. Clin Anat. 2004;17(1):21-25.
10. Portilla Molina AE, Bour C, Oberlin C, Nzeusseu A, Vanwijck R. The posterior interosseous nerve and the radial tunnel syndrome: an anatomical study. Int Orthop. 1998;22(2):102-106.

11. Verhaar J, Spaans F. Radial tunnel syndrome. An investigation of compression neuropathy as a possible cause. $\mathrm{J}$ Bone Joint Surg Am. 1991;73(4):539-544.

12. O'Neil BA, Forsythe ME, Stanish WD. Chronic occupational repetitive strain injury. Can Fam Physician. 2001;47:311-316.

13. Roquelaure Y, Ha C, Rouillon C, Fouquet N, Leclerc A, Descatha A, Touranchet A, et al. Risk factors for upperextremity musculoskeletal disorders in the working population. Arthritis Rheum. 2009;61(10):1425-1434.

14. Svernlov B, Larsson M, Rehn K, Adolfsson L. Conservative treatment of the cubital tunnel syndrome. J Hand Surg Eur Vol. 2009;34(2):201-207.

15. Maggard MA, Harness NG, Chang WT, Parikh JA, Asch SM, Nuckols TK. Indications for performing carpal tunnel surgery: clinical quality measures. Plast Reconstr Surg. 2010;126(1):169-179.

16. Piligian G, Herbert R, Hearns M, Dropkin J, Landsbergis $\mathrm{P}$, Cherniack M. Evaluation and management of chronic work-related musculoskeletal disorders of the distal upper extremity. Am J Ind Med. 2000;37(1):75-93.

17. Roquelaure Y, Raimbeau G, Dano C, Martin YH, PelierCady MC, Mechali S, Benetti F, et al. Occupational risk factors for radial tunnel syndrome in industrial workers. Scand J Work Environ Health. 2000;26(6):507-513.

18. dell'Omo M, Muzi G, Cantisani TA, Ercolani S, Accattoli MP, Abbritti G. Bilateral median and ulnar neuropathy at the wrist in a parquet floorer. Occup Environ Med. 1995;52(3):211-213.

19. Rozmaryn LM, Dovelle S, Rothman ER, Gorman K, Olvey KM, Bartko JJ. Nerve and tendon gliding exercises and the conservative management of carpal tunnel syndrome. J Hand Ther. 1998;11(3):171-179.

20. Katz JN, Fossel KK, Simmons BP, Swartz RA, Fossel $\mathrm{AH}$, Koris MJ. Symptoms, functional status, and neuromuscular impairment following carpal tunnel release. J Hand Surg Am. 1995;20(4):549-555. 